\title{
ENDOTHELIAL AND MICROVASCULAR ABNORMALITIES IN THE ISLET OF NON-OBESE DIABETIC (NOD) MICE: TRANSMISSION AND SCANNING ELECTRON MICROSCOPIC STUDIES
}

Koji Yamamoto ${ }^{1}$, Jun-ichiro Miyagawa ${ }^{1}$, Toshiaki Hanafusa ${ }^{1}$, Naoto ItoH $^{1}$, Atsushi Miyazaki ${ }^{1}$, Chisa Nakagawa ${ }^{1}$, Seilchiro Tarui ${ }^{2}$, Norio Kono ${ }^{1}$ and Yuji Matsuzawa ${ }^{1}$

${ }^{1}$ The Second Department of Internal Medicine, Osaka University Medical School, Osaka, and ${ }^{2}$ Otemae Hospital, Osaka, Japan

\begin{abstract}
We studied morphological changes of endothelial cells and the microvascular system in islets of non-obese diabetic (NOD) mice. Transmission electron microscopic examination of islets of 2-3-week-old NOD mice showed that endothelial cells underlain by lymphocytes had irregular apical surface showing an increased number of microvilli and cytoplasmic processes. These morphological changes were observed even in the islets without any apparent $\beta$-cell damage and supposed to be one of the earliest morphological abnormalities in the islet of NOD mice. In 10-15-week-old NOD mice, numerous lymphocytes infiltrate into the islets where high endothelial venules were observed. This finding suggests that abnormalities of capillaries are related to lymphocytic infiltration in type 1 diabetes. Scanning electron microscopic observation of the three-dimensional vascular architectures in the islets of 2-3-week-old NOD mice revealed normal capillary networks as observed in the control mice, whereas the architecture of 10-15-week-old NOD mice showed marked abnormalities: narrowing or occlusion of the capillary lumen and the development of the post-capillary venules. These findings suggest that abnormalities of endothelial cells and microvasculature in the islet play an important role in the pathogenesis and development of type 1 diabetes in the NOD mouse.
\end{abstract}

Accumulating evidence strongly indicates that endothelial cells may play an important role in the pathogenesis and development of organ-specific autoimmune endocrine diseases $(14,16)$. With respect to type 1 (insulin-dependent) diabetes mellitus (IDDM), dilatation of capillary lumens has been reported in the pancreatic islet of patients with IDDM (2). Hyperexpression of MHC antigens on capillary endothelial cells has also been demonstrated in islets of pancreas specimens obtained at both biopsy and autopsy $(2,11)$. However, it is impossible to study morphologic changes of islets in very early stage of human IDDM. The nonobese diabetic (NOD) mouse, an animal model of type 1 diabetes, has been used in many studies to elucidate the pathogenesis of type 1 diabetes. This strain of mouse exhibits various morphological abnormalities such as insulitis, $\beta$-cell destruction and appearance of retrovirus-like particles in $\beta$-cells $(6,7,9)$. However, neither the changes in the ultrastructure of endothelial cells in the islet nor their pathological significance have yet been clarified. In the present study, islet endothelial cells and vascular architectures of the NOD mouse were examined by transmission and scanning electron microscopy.

\section{MATERIALS AND METHODS}

\section{Animals}

The NOD/shi mouse colony was produced in our animal house and maintained in a specific pathogen-free condition. The cumulative incidence of overt diabetes in our colony was $95 \%$ in females 
and $5 \%$ in males at 40 weeks of age. A total of 20 age-matched ICR mice were used as control.

\section{Transmission Electron Microscopy (TEM)}

Ten female NOD mice and age-matched 12 ICR mice were anesthetized by an intraperitoneal injection of sodium pentobarbital (Nembutal, $100 \mathrm{mg} / \mathrm{kg}$ ) and were perfused via the left ventricle with $3 \%$ glutaraldehyde solution buffered at $\mathrm{pH} 7.4$ with $0.1 \mathrm{M}$ Millonig's phosphate. The NOD mice included 5 non-diabetic mice at 2-3 weeks of age and 5 non-diabetic mice at $10-15$ weeks of age. Islets were excised under the stereomicroscopic observation from the pancreas during subsequent fixation with the same fixative for $2 \mathrm{~h}$ at $4^{\circ} \mathrm{C}$. After secondary fixation with $1 \% \mathrm{OsO}_{4}$ solution buffered at pH 7.4 with $0.1 \mathrm{M}$ Millonig's phosphate for $1 \mathrm{~h}$ at $4^{\circ} \mathrm{C}$, the islets were rinsed with $10 \%$ sucrose solution, block-stained with $3 \%$ aqueous uranyl acetate solution for $30 \mathrm{~min}$ at room temperature, dehydrated in graded concentrations of ethanol series, and embedded in Epon 812 (epoxy resin). At least 5 blocks in each mouse were randomly selected and ultrathin sections (70-80 nm thick) were cut on a Reichert-Jung Ultracut $\mathrm{E}$ ultramicrotome. Then, the sections were doubly stained with aqueous uranyl acetate and Reynolds' lead citrate (18) and were examined in a JEOL JEM-100CX electron microscope.

\section{Scanning Electron Microscopy (SEM)}

Five NOD mice of 2-3 weeks old, 5 NOD mice of 10-15 weeks old, all female, and 12 control female ICR mice were anesthetized by an intraperitoneal injection of sodium pentobarbital (Nembutal, $100 \mathrm{mg} / \mathrm{kg}$ ) and were perfused via the left ventricle with Ringer's solution containing heparin $(2,000$ units/l). Then, a low viscosity solution of methacrylate resin (Mercox, Dainihon Ink and Chemical, Tokyo, Japan) was injected at a rate of $5 \mathrm{ml} / \mathrm{min}$ to make the corrosion casts of the vasculature in the pancreas. The pancreas was then excised and immersed in hot water $\left(60^{\circ} \mathrm{C}\right)$ for $4 \mathrm{~h}$, macerated in a $20 \% \mathrm{KOH}$ solution for 2-3 days, and washed in $\mathrm{H}_{2} \mathrm{O}$. The specimens were immersed in a sodium hypochlorite solution $\left(60^{\circ} \mathrm{C}\right.$, household bleach) for 6-8 h, washed in $\mathrm{H}_{2} \mathrm{O}$, and air-dried. Each corrosion cast was mounted in a metal stub, coated with platinum using an Eiko IB-5 ion coater, and examined in a Hitachi S-800 scanning electron microscope $(12,13)$.

\section{Statistical Analysis}

The length of apical surface and basal plasma membrane of endothelial cells on the photographs were measured by Curvimeter (Uchida Yoko, Tokyo, Japan) at a magnification of $\times 7,200-12,000$. Cytoplasmic processes, microvilli, and fenestration of endothelial cells were counted and the number of cytoplasmic processes, microvilli, and fenestration per $1 \mathrm{~mm}$ apical surface were calculated. Statistical analysis was performed by Wilcoxon Signed Rank test.

\section{RESULTS}

\section{Transmission Electron Microscopy}

Endothelial cells in islets of ICR mice at any age showed relatively smooth apical surface, thin cytoplasm, and well-developed fenestration by TEM. In the islets of 2-3-week-old female NOD mice, endothelial cells with no lymphocyte infiltration in the vicinity had smooth apical surface (Fig. 1a), whereas those underlain by lymphocytes had irregular surface showing an increased number of microvilli and cytoplasmic processes: such endothelial cells had a decreased number of fenestration (Fig. $1 \mathrm{~b}$ and Table 1). To evaluate quantitatively the increase of apical surface, we calculated the ratio of the length of apical surface divided by that of basal plasma membrane. The ratio was increased in the endothelial cells underlain by lymphocytes compared with that in endothelial cells with no lymphocytes in the vicinity $(1.26 \pm 0.04$ [mean $\pm \mathrm{SE}$, $\mathrm{n}=10$ ] vs $0.86 \pm 0.04$ [ $\mathrm{n}=45], P<0.01$ ). By light microscopy, no feature of insulitis could be recognized in any islets examined.

In 10-15-week-old NOD mice, almost all the islets were infiltrated by numerous lymphocytes, some of which showed mitosis and blast formation. Immature (pale) secretory granules without perigranular halo were frequently observed in $\beta$-cells (Fig. 2). Endothelial cells underlain by a few lymphocytes also showed an increased number of microvilli and cytoplasmic processes as shown in the islets of NOD mice of 2-3 weeks of age. However, the following findings were completely different from those of 2-3 weeks of age. Endothelial cells in the area invaded by numerous lymphocytes showed increased thickness of cytoplasm without detectable fenestration (Fig. 3). Many lymphocytes were found penetrating such endothelial cells which were considered to be high endothelial cells in post-capillary venules. Such endothelial cells 

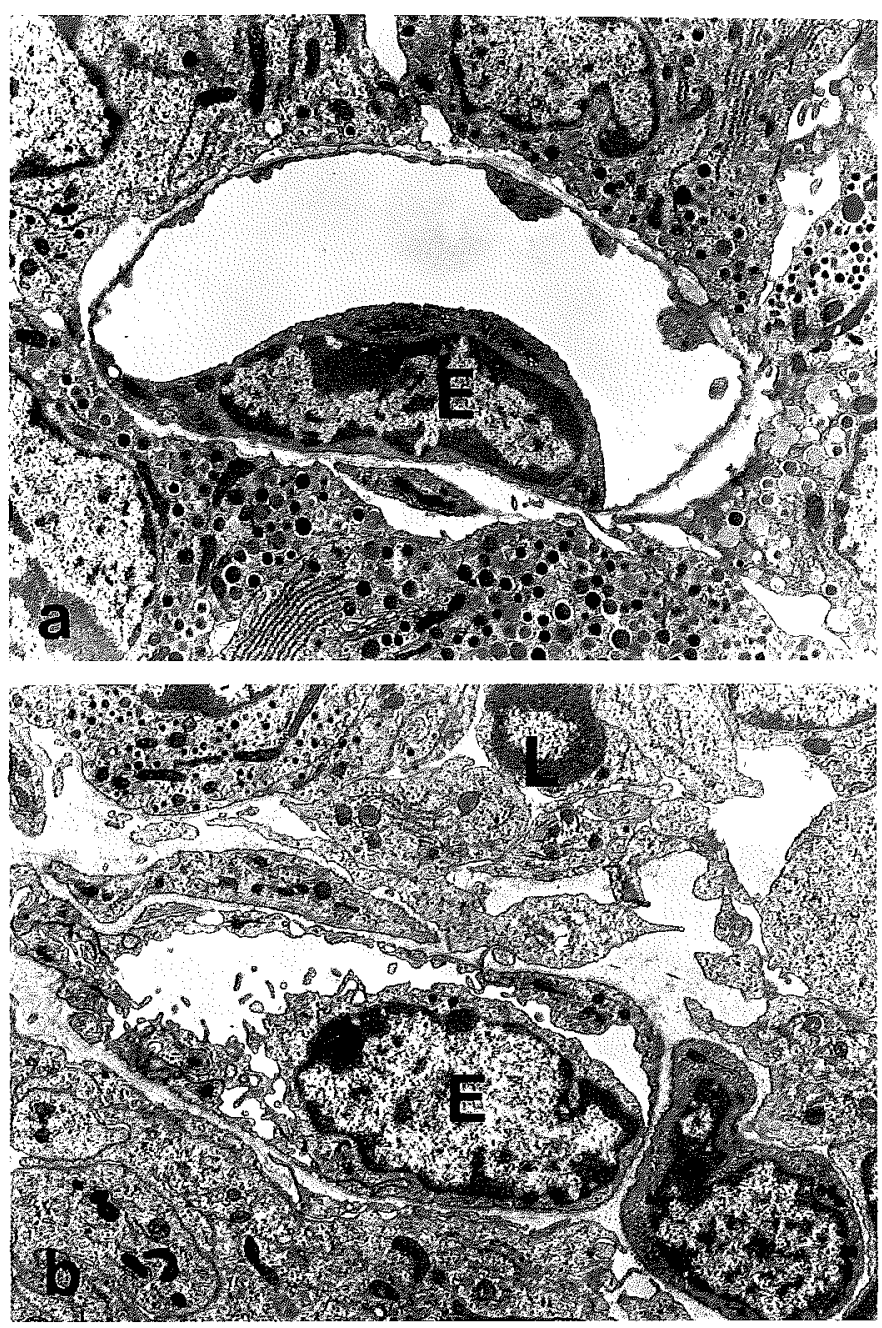

Fig. 1 a: Capillary endothelial cells $(E)$ in the islet of a 3week-old NOD mouse. $\times 4,800$. b: Capillary endothelial cells in the islet of a 3-week-old NOD mouse. Endothelial cells (E) underlain by lymphocytes (L) have an increased number of microvilli and cytoplasmic processes. $\times 4,300$

Table 1 Statistical Analysis of the Numbers of Microvilli, Cytoplasmic Processes, and Fenestration

\begin{tabular}{cccc}
\hline & $\begin{array}{c}\text { Microvilli } \\
(/ \mathrm{mm})\end{array}$ & $\begin{array}{c}\text { Cytoplasmic } \\
\text { processes }(/ \mathrm{mm})\end{array}$ & $\begin{array}{c}\text { Fenestration. } \\
(/ \mathrm{mm})\end{array}$ \\
\hline $\begin{array}{c}\text { EC-L }(+) \\
\mathrm{n}=17\end{array}$ & $68.8 \pm 15.0$ & $36.6 \pm 10.8$ & $688 \pm 132$ \\
EC-L $(-)$ & $*$ & $f$ & $*$ \\
$\mathrm{n}=62$ & $37.5 \pm 6.2$ & $24.4 \pm 5.3$ & $1,224 \pm 98$ \\
\hline
\end{tabular}

Values are means \pm SE. EC-L $(+)$ : Endothelial cells underlain by lymphocytes. EC-L (-): Endothelial cells with no lymphocytes in the vicinity. ${ }^{*}, P<0.01 ; f, P<0.05$ 


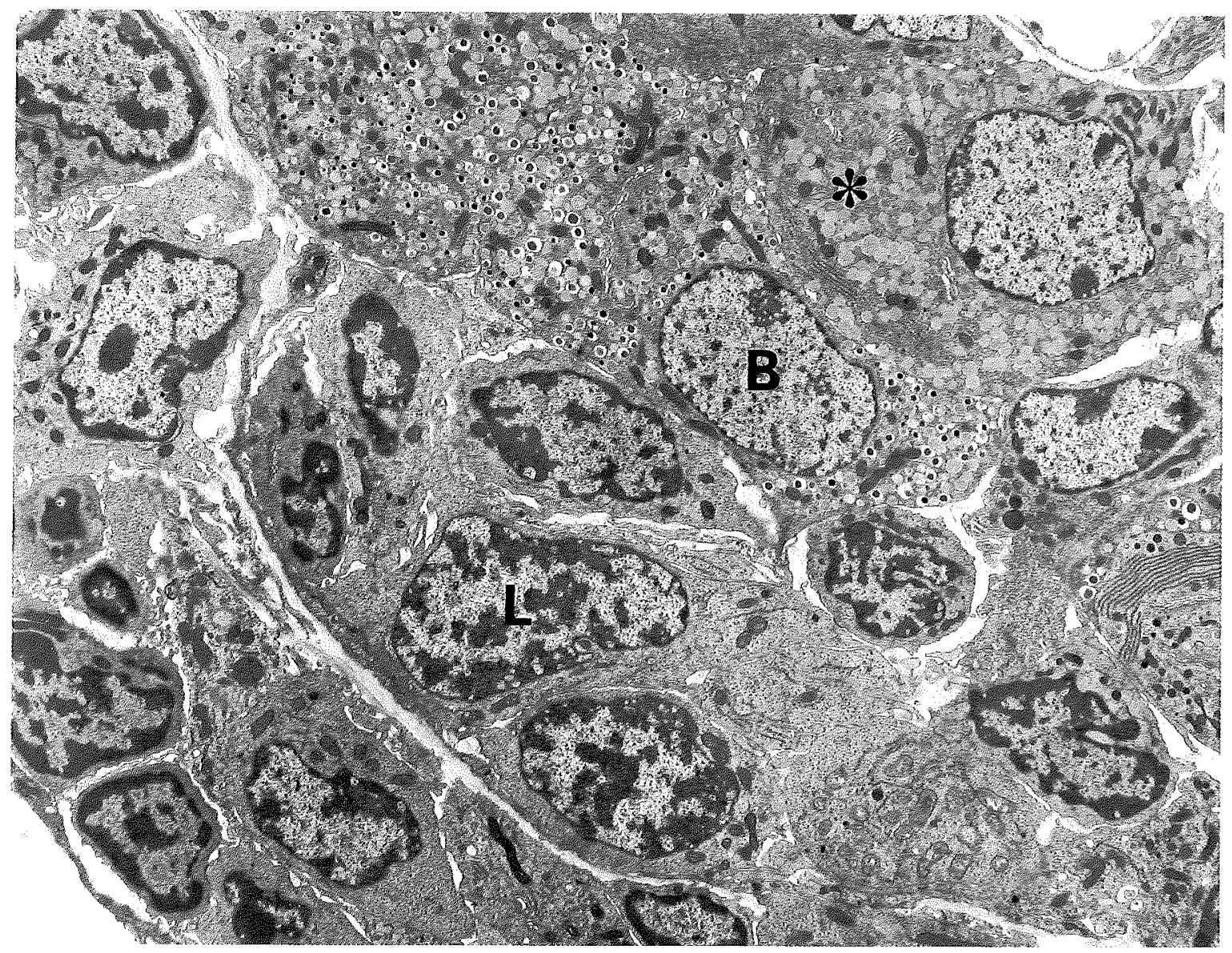

Fig. 2 Islet of a 10-week-old NOD mouse. Many lymphocytes (L) infiltrate in and around the islet. Pale granules with low electron density in $\beta$-cells $\left(^{*}\right)$ are present. $\beta$-Cell (B) with normal secretory granules. $\times 3,500$

sometimes had dense bodies and endothelial cells themselves were sometimes seen protruding into the vascular lumen (Figs. 4 and 5). Thus, in the lymphocyte-infiltrating lesion, venules with characteristic features of post-capillary venules developed, and such long post-capillary venules were never observed in the islets without massive lymphocytic infiltration.

\section{Scanning Electron Microscopy}

Three-dimensional aspects of the vascular system in the pancreas of ICR mice were examined by SEM. In most islets, capillaries formed a wellramified network.

Three-dimensional microvascular architectures of 2-3-week-old female NOD mice showed normal capillary networks as observed in ICR mice (Fig. 6a). The capillary network in the islet of 10-15- week-old mice showed marked architectural abnormalities. Some areas appeared almost vacant and consisted of extremely scanty vascular networks. The networks were formed only by dilated venules which connected the center and the periphery of the islet. These vacant areas might be the sites of lymphocyte infiltration, since light microscopic examination revealed that a part of the islet was replaced by accumulated lymphocytes in almost all the islets at this week of age. Vascular lumens in the vicinity of the vacant area were irregular, and showed narrowing or occlusion in some parts (Fig. 6b).

\section{DISCUSSION}

In various immune phenomena, vascular endothelial cells play several important roles such as cell adhesion and migration of circulating lymphocytes 


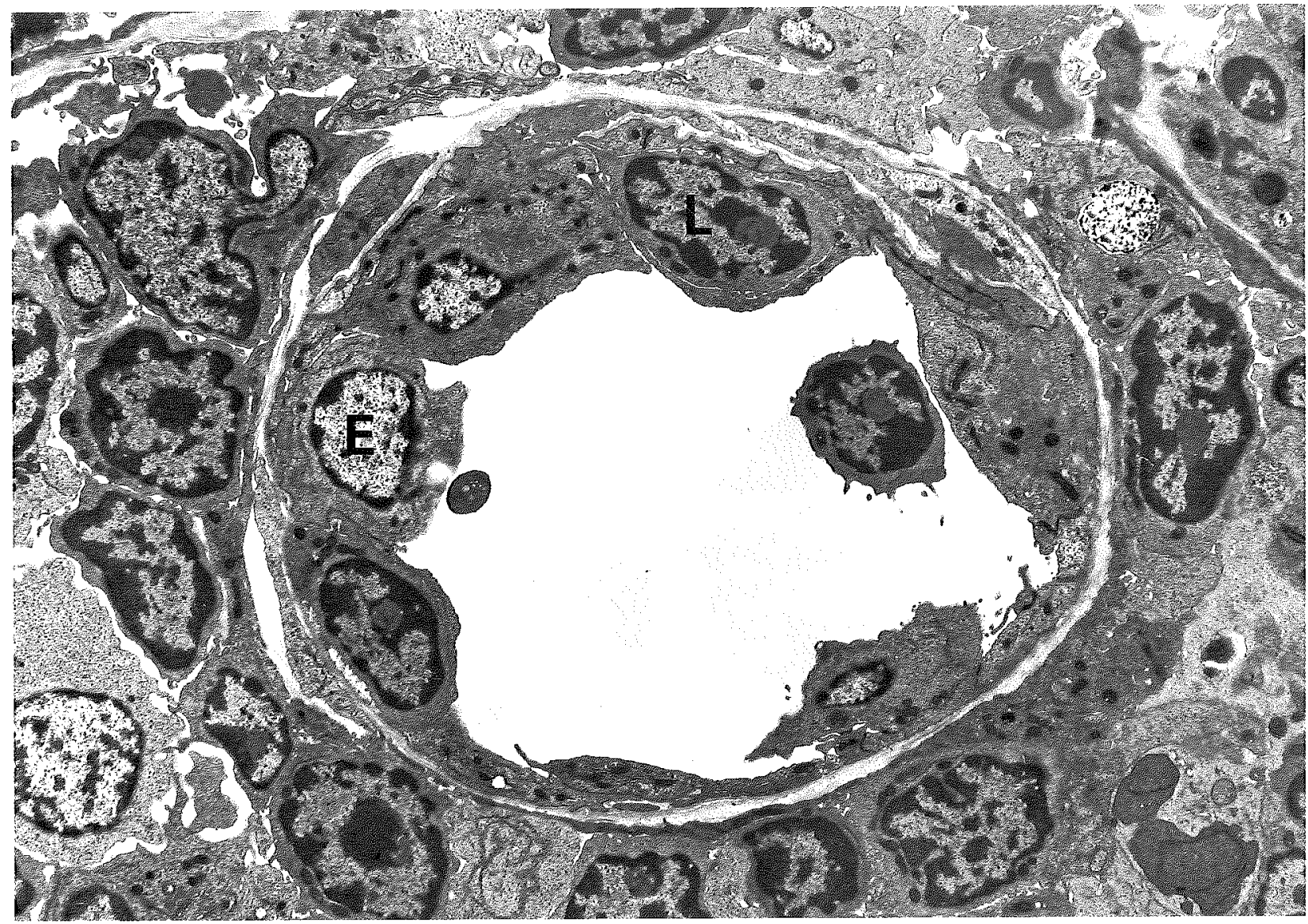

Fig. 3 Endothelial cells surrounded by massive lymphocytic infiltrate in a 10-week-old NOD mouse. Lymphocytes (L) are traversing the endothelial cells $(\mathrm{E}) . \times 3,800$

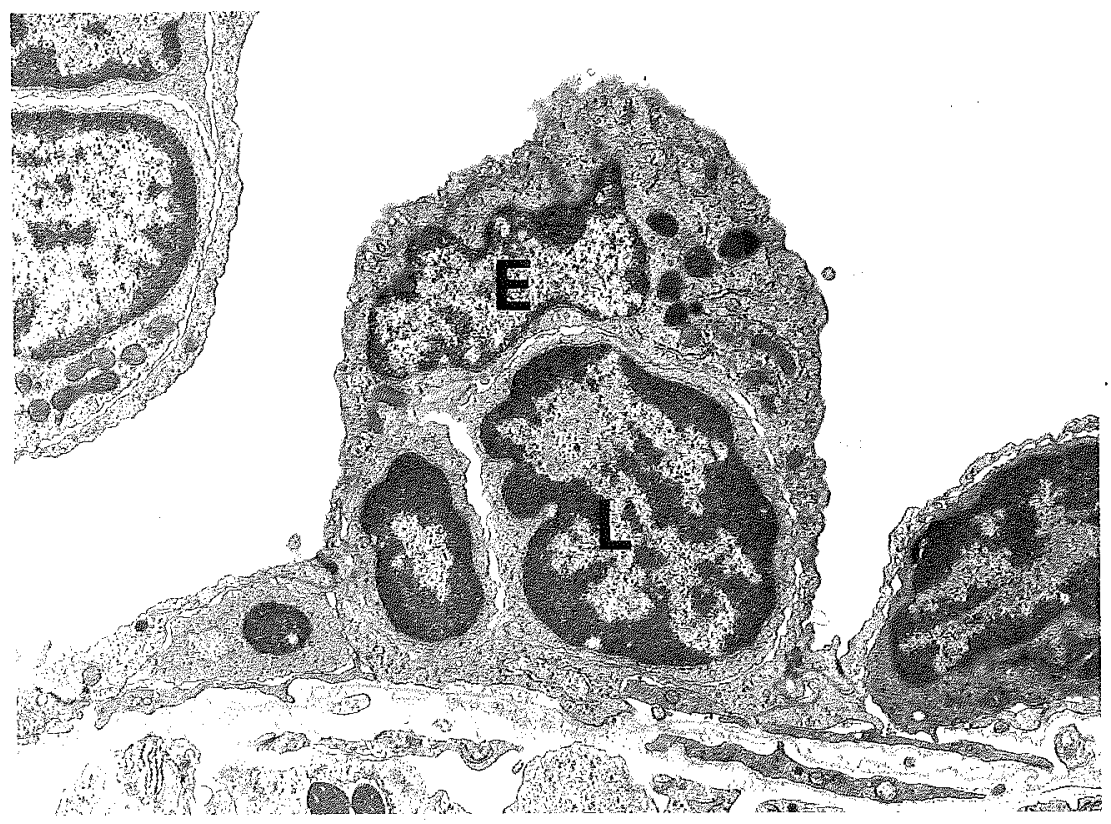

Fig. 4 Endothelial cells (E) with dense bodies in insulitis in a 10-week-old NOD mouse, showing typical features of cells of high endothelial venules. L, Lymphocyte. $\times 6,400$ 


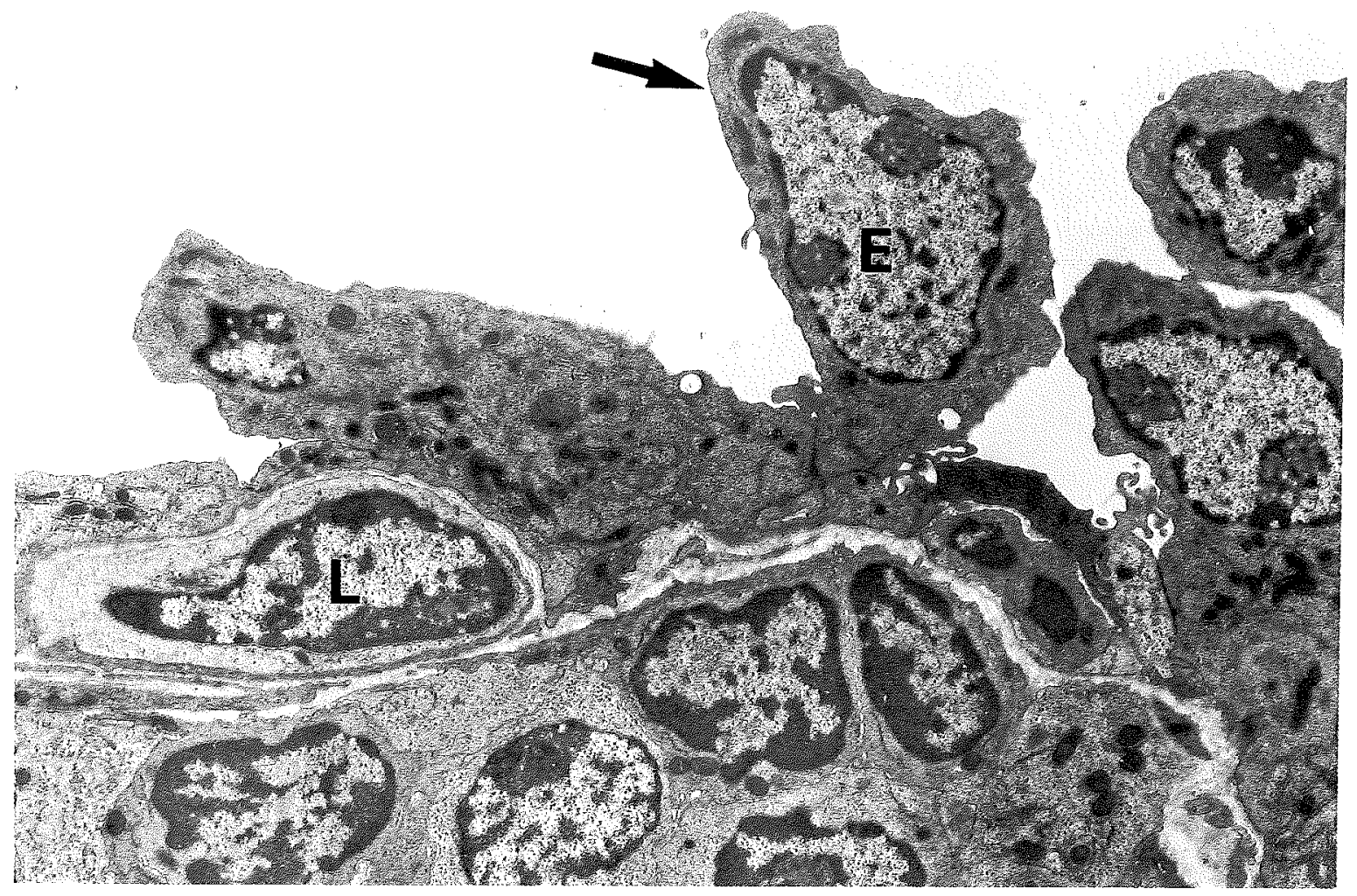

Fig. 5 Endothelial cells surrounded by massive lymphocytic infiltrate in a 10-week-old NOD mouse. Endothelial cells (E) protrude into the vascular lumen (arrow). L, Lymphocyte. $\times 5,900$

(10). The present study has demonstrated for the first time that endothelial cells in the islet of the NOD mouse accompanied substantial morphologic alteration in the early age even when no apparent morphologic evidence for $\beta$-cell damage was detected. Islet endothelial cells at 2-3 weeks of age showed an increased number of microvilli or apical cytoplasmic processes, and a decreased number of fenestration if lymphocytes were seen in the vicinity. These changes are thus supposed to be some of the earliest phenomena in the process of insulitis and $\beta$-cell destruction.

In the islets of NOD mice, infiltrating mononuclear cells mainly consist of lymphocytes. Our electron microscopic examination revealed that these lymphocytes appeared as early as 2-3 weeks of age. It was first reported by Marchesi et al. (15) that in lymph nodes of rats, lymphocytes penetrated the endothelium of the post-capillary venules, entering the endothelial cells and traversing their cytoplasm, and that they did not pass through the intercellular junctions between endothelial cells. This report was confirmed by another study (4). Such postcapillary venules are called high endothelial venules (HEVs) which consist of distinct endothelial cell type characterized by the cuboidal shape, welldeveloped Golgi apparatus, dense bodies, a few elongated mitochondria, and having the capacity to allow lymphocytes to pass from the bloodstream into lymphoid tissues $(5,19)$. We have shown that in NOD mice at 10-15 weeks of age, numerous mononuclear cells infiltrate into the islets, and that lymphocytes penetrate the cytoplasm of the endothelial cells with relatively thick cytoplasm. These findings are consistent with those by Marchesi et al. (15). Our finding that lymphocytes are never seen passing through the intercellular junctions is contrary to the report by Yamaguchi et al. (22) who showed that most migrating lymphocytes traversed the intercellular junctions between endothelial 

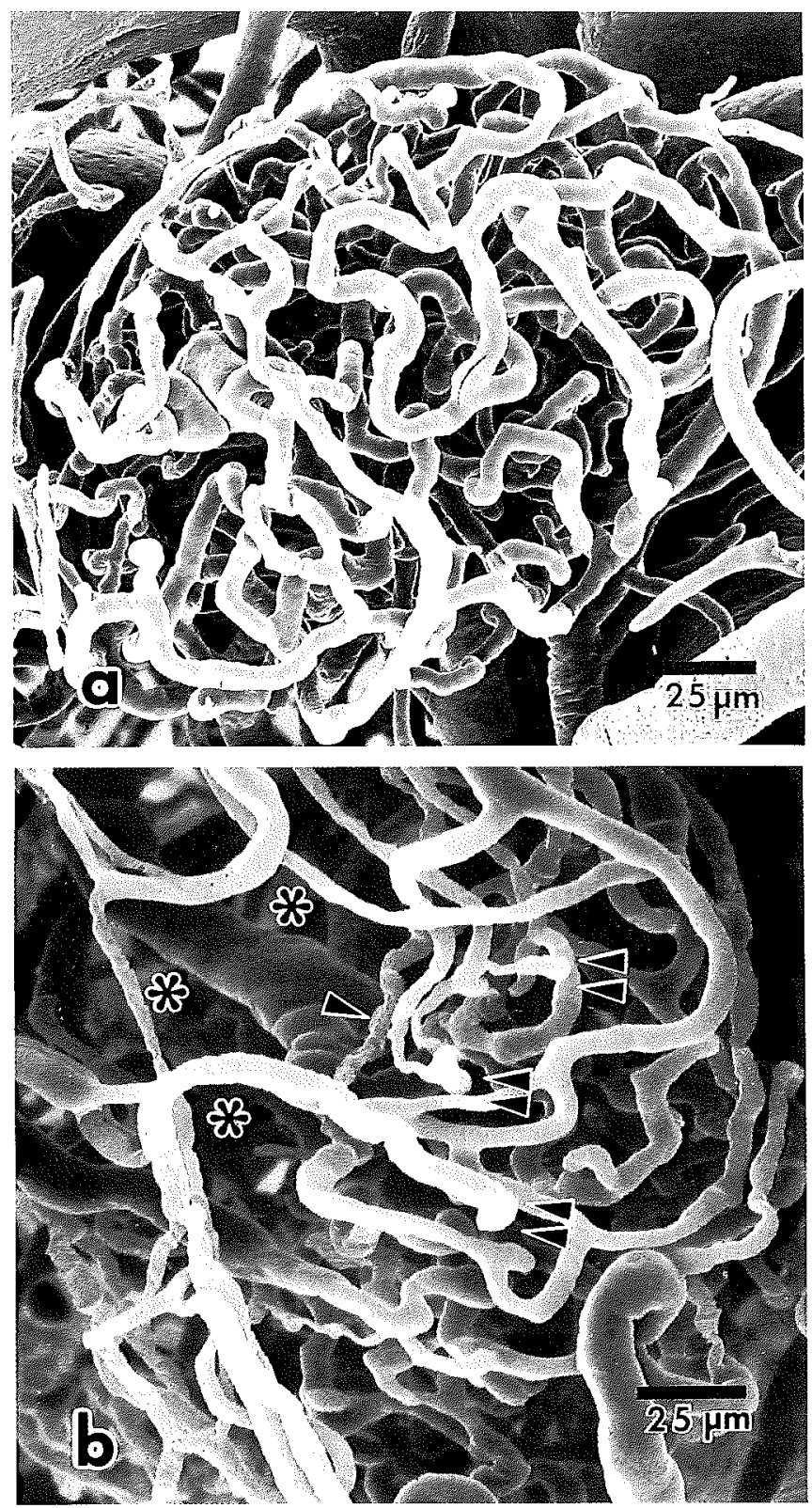

Fig. 6 a: Islet capillary network in a 3-week-old NOD mouse. Three-dimensional structure of the capillary network is the same as that of control ICR mice. Well-ramified capillary lumen is relatively smooth. $\times 520$. b: Islet capillary network in a 10 -week-old NOD mouse. Space of a coarse capillary network $(*)$, irregular vascular lumen (arrowhead), and possible sites of obstruction in the capillaries (double arrowheads) are recognized. $\times 520$

cells of post-capillary venules of the Peyer's patch in the mouse. HEVs were reported to appear very late in spontaneous autoimmune thyroiditis in BB (Bio-breeding) rats (14). In the insulitis of NOD mice, however, such HEVs were observed as early as 10 weeks, and thus these HEVs are considered to play more important role in the development of insulitis and diabetes compared with BB rat thyroiditis. In this study, we succeeded for the first time by making corrosion casts in demonstrating the threedimensional architecture of normal capillary networks in pancreatic islets of mice. Our observation 
by SEM that the capillaries of mouse islets form rich networks is consistent with the previous findings studied in other species or by other methods $(1,3,8,17,20)$. The islet capillary networks of NOD mice with insulitis showed marked abnormalities such as scanty vascular networks formed only by dilated post-capillary venules. The development of post-capillary venules at the site of lymphocytic infiltration may be the result of either angiogenesis or the elongation of the normal islet post-capillary venules, since the post-capillary venules in normal rodents are very short and seen only around the islet (1).

In the present study, irregular surface of the vascular lumen was recognized by TEM in the lymphocyte-infiltrated lesion (Figs. 4 and 5) and by SEM in the vicinity of the scanty capillary network (Fig. 6b). The irregular surface of the vascular lumen is considered to reflect the lymphocyte penetration through the venular wall as has been shown in sheep thymus (21). Thus, the irregular surface may reflect the lymphocyte penetrating through high endothelial cells in insulitis.

In islets of pancreas biopsy specimens from newly diagnosed type 1 diabetic patients, abnormalities of capillary endothelial cells such as the hyperexpression of MHC antigens were demonstrated (11). This evidence suggests that islet endothelial cells are involved in the immune system and may play a role in the process of $\beta$-cell destruction. Thus, the detailed analysis of islet endothelial cells in NOD mice is expected to provide further insights into the mechanism of $\beta$-cell destruction in humans.

In conclusion, ultrastructural changes in endothelial cells were found in the islet of NOD mice as early phenomena in the process of insulitis. Such changes together with abnormal microvasculature in the islet might play an important role in the pathogenesis and development of type 1 diabetes in the NOD mouse.

We thank Dr M. Imada (Nihon University School of Medicine, Second Department of Anatomy) for helpful discussions and technical advice. This work was supported in part by the Scientific Research Fund from the Ministry of Education, Science and Culture of Japan.

Received 20 April 1992; and accepted 12 June 1992

\section{REFERENCES}

1. Bonner-Weir S. and Orci L. (1982) New perspectives on the microvasculature of the islets of Langerhans in the rat.
Diabetes 31, 883-889

2. Bottazzo G. F., Dean B. M., MeNally J. M., MacKay E. H., Swift P. G. F, and Gamble D. R. (1985) In situ characterization of autoimmune phenomena and expression of HLA molecules in the pancreas in diabetic insulitis. $N$. Engl. J. Med. 313, 353-360

3. Bunnag S. C., Bunnag S. and Warner N. E. (1963) Microcirculation in the islets of Langerhans of the mouse. Anat. Rec. 146, 117-123

4. Cho Y. and De Bruyn P. P. H. (1979) The endothelial structure of the postcapillary venules of the lymph node and passage of lymphocytes across the venule wall. J. Ultrastr. Res. 69, 13-21

5. Freemont A. J. and Ford W. L. (1985) Functional and morphological changes in post-capillary venules in relation to lymphocytic infiltration into BCG-induced granulomata in rat skin. J. Pathol. 147, 1-12

6. Fujino-Kurihara H., Fujita H., Hakura A., NonaKa K. and TARUI S. (1985) Morphological aspects on pancreatic islets of non-obese diabetic (NOD) mice. Virchows Arch. $B$. Cell Pathol. 49, 107-120

7. Fujita H., Fujino H., Nonaka K., Tarui S. and Tochino Y. (1984) Retrovirus-like particles in pancreatic B-cells of NOD (non-obese diabetic) mice. Biomedical Res. 5, 6770

8. Fujita T. and Murakami T. (1973) Microcirculation of monkey pancreas with special reference to the insuloacinar portal system. A scanning electron microscope study of vascular casts. Arch. Histol. Japon. 35, 255-263

9. Funita T., Yui R., Kusumoto Y., Serizawa Y., Makino S. and Tochino Y. (1982) Lymphocytic insulitis in a 'nonobese diabetic (NOD)' strain of mice: An immunohistochemical and electron microscope investigation. Biomedical Res. 3, 429-443

10. Gowans J. L. and Knight E. J. (1964) The route of recirculation of lymphocytes in the rat. Proc. Roy. Soc. Lond. Ser. B. 159, 257-282

11. Hanafusa T., Miyazaki A., MiYagawa J., Tamura S., Inada M., Yamada K., Shinji Y., Katsura H., Yamagata K., Itoh N., Asakawa H., Nakagawa C., Otsuka A., Kawata S., Kono N. and Tarui S. (1990) Examination of islets in the pancreas biopsy specimens from newly diagnosed Type 1 (insulin-dependent) diabetic patients. Diabetologia 33, 105-111

12. Imada M., Kurosumi M. and Fujita H. (1986) Threedimensional aspects of blood vessels in thyroids from normal, low iodine diet-treated, TSH-treated, and PTUtreated rats. Cell Tissue Res. 245, 291-296

13. Imada M., Tatsumi H. and Fujita H. (1987) Scanning electron microscopy of vascular architecture in the gastric mucosa of the golden hamster. Cell Tissue Res. 250, 287293

14. Kabel P. J., Voorbis H. A. M., de HaAn-Meulman M., Pals S. T. and Drexhage H. A. (1989) High endothelial venules present in lymphoid cell accumulations in thyroids affected by autoimmune disease: a study in men and BB rats of functional activity and development. J. Clin. Endocrinol. Metab. 68, 744-751

15. Marchesi V. T. and Gowans J. L. (1964) The migration of lymphocytes through the endothelium of venules in lymph nodes: an electron microscope study. Proc. Roy. Soc. Lond. Ser: B. 159, 283-290

16. Miyazaki A., Hanafusa T., Itoh N., Miyagawa J., Kono N., Tarui S., KiYotaki C. and Yoshizaki K. (1989) 
Demonstration of interleukin- $\beta$ on perifollicular endothelial cells in the thyroid glands of patients with Graves' disease. J. Clin. Endocrinol. Metab. 69, 738-744

17. Ohtani O. and Fujita T. (1980) Microcirculation of the pancreas with special reference to periductular circulation. A scanning electron microscope study of vascular casts. Biomedical Res. 1, 130-140

18. ReYNolds E. S. (1963) The use of lead citrate at high $\mathrm{pH}$ as an electron-opaque stain in electron microscopy. J. Cell. Biol. 17, 208-212

19. Umetani Y. (1977) Postcapillary venule in rabbit tonsil and entry of lymphocytes into its endothelium: A scanning and transmission electron microscope study. Arch. Histol. Japon. 40, 77-94

20. WeAver F. C. and Sorenson R. L. (1989) Islet vasculature in atrophic pancreas: Evidence for coexisting parallel and serial (insuloacinar) angioarchitecture. Pancreas 4, 10-22

21. YamaguCHI K. and MiYasaKa M. (1988) Microvasculature of the sheep thymus. Adv. Exp. Med. Biol. 237, 571-575

22. Yamaguchi K. and Schoefl G. I. (1983) Blood vessels of the Peyer's patch in the mouse: III. High-endothelium venules. Anat. Rec. 206, 419-438 